\title{
Research on Coordination of Fresh Agricultural Product Supply Chain considering Fresh-Keeping Effort Level under Retailer Risk Avoidance
}

\author{
Yangang Feng $\mathbb{D D}^{1,2} \mathrm{Yi} \mathrm{Hu}^{1}$ and $\mathrm{Lin} \mathrm{He}^{3}$ \\ ${ }^{1}$ School of Business, Fuyang Normal University, Fuyang 236037, China \\ ${ }^{2}$ Key Laboratory of Regional Logistics Planning and Modern Logistics Engineering of Anhui Province, Fuyang 236037, China \\ ${ }^{3}$ School of Information Engineering, Fuyang Normal University, Fuyang 236037, China
}

Correspondence should be addressed to Yangang Feng; fengyg@bupt.edu.cn

Received 26 January 2021; Revised 6 April 2021; Accepted 7 May 2021; Published 24 May 2021

Academic Editor: Viktor Avrutin; viktor.avrutin@ist.uni-stuttgart.de

Copyright $(2021$ Yangang Feng et al. This is an open access article distributed under the Creative Commons Attribution License, which permits unrestricted use, distribution, and reproduction in any medium, provided the original work is properly cited.

Considering that the demand for fresh agricultural products is affected by product freshness and price, a two-level fresh agricultural product supply chain decision model consisting of a risk-neutral supplier and a risk-averse retailer is constructed. In order to increase consumer demand for fresh agricultural products, the supplier will make appropriate efforts to preserve the freshness of agricultural products. The optimal fresh-keeping effort level of the supplier and the optimal pricing decision of the retailer under the centralized decision-making and decentralized decision-making modes were studied, respectively; through the design of traditional cost-sharing contracts, traditional cost and revenue-sharing contracts, and cost-sharing and compensation strategies, the supplier was encouraged to improve their fresh-keeping effort. The research shows that the traditional cost-sharing contract and the traditional cost-benefit sharing contract cannot coordinate the supply chain. Under the strategy of cost sharing and compensation, when the amount of compensation meets certain conditions, the coordination of supply chain can be realized. Finally, the important parameters of the model are analyzed by numerical simulation.

\section{Introduction}

Fresh agricultural products are indispensable commodities in daily life and occupy an extremely important position in the retail consumption market. Due to the perishable nature of fresh agricultural products and the immaturity of freshkeeping technology, fresh agricultural products are severely lost during transportation and sales. According to statistics, the annual loss rate of fresh agricultural products in China is between $25 \%$ and $35 \%$ [1]. For fresh agricultural product supply chain companies, it is particularly important to maintain the freshness of products and prevent them from decay and deterioration. Fresh agricultural product suppliers are limited by their own resources and cannot provide more funds or technology to maintain product freshness. Retailers, as important members of the supply chain, should also make efforts to keep the freshness of agricultural products. While improving product quality and customer satisfaction, retailers can also contribute to the improvement of their own and the overall revenue of the supply chain. Therefore, it is of great theoretical and practical significance to study the cost sharing of fresh agricultural products preservation efforts among members of the fresh agricultural product supply chain for reducing product losses and improving the operation efficiency of the supply chain.

Because fresh agricultural products have a short life cycle and high loss rate, market demand is greatly affected by the freshness of agricultural products and other characteristics; coupled with the occurrence of some emergencies, the fresh agricultural product supply chain has a greater risk. For example, the "COVID-19 epidemic" occurred at the beginning of 2020, which led to the closure of catering enterprises, the delay of the commencement of enterprises and schools, and a significant reduction in the consumption demand of fresh agricultural products, resulting in heavy losses for many producers and retailers of fresh agricultural 
products [2]. The existence of supply chain risk of fresh agricultural products leads to the risk aversion characteristic of supply chain node enterprises when making decisions. How will the risk aversion characteristics of decision makers affect the pricing and product preservation decisions of the fresh product supply chain? Under the condition of risk aversion by decision makers, how to design a reasonable supply chain contract to improve the operation efficiency of the supply chain?

To answer the above questions, this paper constructs a Stackelberg game model between fresh products supplier and retailer under the assumption of retailer's risk aversion and analyzes the impact of retailer's risk aversion characteristics on the prices of fresh agricultural products, supplier's preservation efforts, and the efficiency of a supply chain. The paper also studies overall benefits of the supply chain system by using mixed contract of cost-sharing and compensation strategies.

The structure of this paper is as follows: the second part is literature review; the third part is model assumption; the fourth part is model establishment and analysis, including a centralized decision model and a decentralized decision model; the fifth part is designing traditional cost-sharing contracts, cost-sharing and revenue-sharing contracts, and mixed contracts of cost-sharing and compensation strategies; the sixth part is the numerical simulation analysis; and the seventh part is the summary of the article.

\section{Literature Review}

Previous researches in this field can be summarized into the following three aspects: (1) operational and management issues of fresh agricultural product supply chain; (2) fresh agricultural product supply chain risk aversion issues; (3) supply chain coordination issues.

\subsection{Operational and Management Issues of Fresh Product} Supply Chain. There are a lot of literatures on the operational and management issues of the fresh agricultural product supply chain, mainly related to the inventory decision, pricing decision, and preservation-technology investment decision. Ferguson et al. [3] used the economic order batch model to study the ordering of fresh agricultural products. Bakker et al. [4] reviewed the inventory control issues of the fresh agricultural product supply chain. Shen et al. [5] studied the best supply and replenishment strategy under the "agricultural super docking" model. Su and Ma [6] studied the pricing and inventory decision-making of retailers with the assumption that stock-outs are allowed and partially delayed.

Taking into account the impact of price on demand, $\mathrm{Lu}$ et al. [7] studied the ordering and pricing strategies of the fresh produce supply chain. Wen and Tao [8] studied the pricing of fresh agricultural products supply chain affected by quantity loss under the condition that two products produced by a single supplier are substitutable, and the demand is affected by its own price, freshness, and the price of substitutes. Li and Fan [9] considered factors such as product loss and demand and solved the problem of pricing and ordering decisions under the three pricing models. Hu and Zhou [10] aimed at the issues of easy depletion, high supply risk, and difficulty in replenishment of organic agricultural products, constructed a single-source procurement of organic agricultural products and a dual-source procurement model of organic and ordinary agricultural products with one-way substitution, and obtained the retailer's optimal order strategy and maximum expected profit under different conditions. Deng [11] considered the influence of time and spoilage rate of agricultural products and studied inventory decision-making. Liu et al. [12] studied the ordering and inventory decisions of seasonal fresh agricultural products. Makoena and Olufemi [13] studied the pricing, ordering, and inventory decisions of the three-level fresh produce supply chain.

\subsection{Risk Aversion in the Fresh Agricultural Products Supply} Chain. The deterioration of fresh agricultural products makes the fresh agricultural product supply chain more risky. Some scholars focus their research on risk aversion in the fresh agricultural product supply chain. Sheffi [14] used transaction cost theory and resource dependence model to discuss the supply risk management of fresh agricultural product supply chain and pointed out that proactive procurement management is beneficial to control fresh agricultural product supply risk. Bjørn and Bendiksen [15] conducted relevant empirical studies on the supply chain of Norwegian fish products and found that the application of relevant new technology and equipment will greatly improve product quality, avoid supply chain risks, and increase product competitiveness. Arthon and Kannapon [16] took Thailand as an example to study the risk management of seafood supply chain. Jia et al. [17] studied the risk identification and control of fresh agricultural product supply chain through social network analysis technology. Feng et al. [18] used neural networks to assess the risks of the fresh grape supply chain from the perspective of sustainable development.

Most of the above-mentioned literatures are qualitative analysis of the risk management issues of the fresh product supply chain. In recent years, some scholars have used the mean-variance theory $[19,20]$ and conditional value-at-risk (CVaR) [21] and other theoretical tools to analyze the impact of decision-makers' risk aversion attitudes on supply chain members' decisions and supply chain performance. Raza and Govindaluri [19] used the mean-variance theory to study the optimal decision of dual-channel green supply chain in the case of risk aversion of manufacturers and retailers. Liu and Yue [20] used the meanvariance theory to study the pricing decision-making problem of the dual-channel agricultural product supply chain in the situation of supplier risk aversion and the influence of the supplier's risk aversion characteristics on its optimal decision. Ye et al. [21] established a decisionmaking function for farmers with risk aversion based on $\mathrm{CVaR}$ and analyzed the optimal decision-making behavior of farmers and companies. 
2.3. Supply Chain Coordination Issues. Supply chain coordination has been a research hotspot in academic circles in recent years, and many scholars have conducted in-depth researches on this issue. Cachon [22] studied how to use supply chain contracts to coordinate supply chains. Yan et al. [23] studied the coordination of the fresh produce supply chain while considering strategic consumer behavior. Xiao et al. [24] studied the optimization and coordination of the fresh product supply chain based on cost insurance and freight management mode when the decision maker is riskneutral under uncertain long-distance transportation conditions. Ma et al. [25] studied a three-level supply chain system of fresh agricultural products composed of a supplier, a third-party logistics service provider (TPLSP), and a retailer under the condition of decision-makers' risk neutrality and designed a system based on the cost and revenue sharing. Coordination contract shows that, under the designed contract, the sales of the supply chain can increase significantly, and all supply chain members can benefit from Pareto incentives. Moon et al. [26] studied the investment and coordination decision-making of fresh agricultural product supply chain. Wang et al. [27] assumed that the demand for fresh agricultural products is affected by product freshness and price, considered the joint impact of the supplier's freshness effort level and the time required to transport the product on freshness, and studied how to use cost-sharing contract and Nash bargaining under the costsharing contract to coordinate the supply chain. Mohammadi et al. [28] developed a new coordination mechanism based on preservation-technology investment, and the results show that the coordination mechanism can not only reduce waste, but also increase the profits of fresh product supply chain members. Ye et al. [29] designed a supply chain portfolio contract consisting of revenue-sharing contract, production cost-sharing contract, and margin contract and studied the optimal production and price decision-making problem of the contract agricultural supply chain composed of agribusiness and risk-averse farmers.

Through combing the existing related literature, we can find that most of the researches have only considered one or two of the three factors of the decision-maker's preservation effort level, time factor, and decision-maker's risk aversion characteristics when constructing the model. Few studies include the above three factors into one model at the same time. Based on the above reasons, and based on the assumption that retailers have risk aversion characteristics, this article considers that the freshness of the product is affected by the decision-maker's effort level and time factors, constructs a fresh product supply chain decision model, and studies how to use the mixed contract of cost-sharing and compensation strategies to coordinate the supply chain. Compared with the existing literatures, the novelty of this paper is that it takes into account the supplier's freshkeeping efforts, the impact of transportation time on product freshness, and the risk aversion characteristics of the retailer in one model, and the model constructed is more consistent with the reality.

The contribution of this article is mainly reflected in the following two aspects. First, this article introduces the retailer's risk aversion characteristics into the fresh product supply chain model, analyzes the influence of the retailer's risk aversion on the optimal decision-making of the supply chain, and enriches the fresh product supply chain management theory. Second, some related researches mostly assume that the freshness of the product is affected by the decision-maker's effort to preserve freshness but ignored the influence of time factor on the freshness of products. This article assumes that the freshness of the product is also affected by transportation time, and if the transportation time exceeds a certain threshold, the rate of deterioration of the product will become faster and faster, and hence, the model constructed in this paper is more realistic.

\section{Model Assumptions}

We consider a fresh product supply chain system consisting of a supplier ( $\mathrm{S}$ ) and a retailer (R), the freshness of fresh agricultural products decays with transportation time, and market demand, which is affected by product freshness and sales prices. Retailers place orders with supplier based on their predicted market demand, and suppliers are responsible for the transportation of goods. In order to ensure the freshness of the product, the supplier will take some freshkeeping measures during transportation. The freshness of the product is related to the supplier's fresh-keeping effort level, and the transportation costs and risks are borne by the supplier. For the convenience of calculation, suppose that the retailer's cost is zero. The main symbols used in the text are shown in Table 1:

Make the following assumptions:

Assumption 1. With reference to the practice in [12], the relationship between the supplier's fresh-keeping effort and its fresh-keeping cost input is $C(e)=(\mu / 2) e^{2}$.

Assumption 2. With reference to the market demand function model in [26], it is assumed that consumer demand is sensitive to both the price $p$ and freshness of fresh agricultural products $\theta$, and the uncertainty of the market is taken into account. The market demand function of fresh agricultural product is expressed as $d=a-b p+k \theta(e, t)+\varepsilon$.

Here, $\varepsilon$ represents the uncertainty of market demand, assuming $\varepsilon \sim N\left(0, \sigma^{2}\right)$, its mathematical expectation is 0 and the variance is $\sigma^{2}$.

Assumption 3. It refers to the practice of [26] and defines the relationship between freshness of fresh agricultural products $\theta$, effort level of preservation $e$ and transportation time $t$ as $\theta(e, t)=\left(\beta e /\left(1+\alpha t^{2}\right)\right)$; that is when the transportation time is infinite, no matter what value the preservation effort takes, the freshness will approach 0 . Because $(\partial \theta(e, t) / \partial t)$ $=-\left(2 \alpha \beta e t /\left(1+\alpha t^{2}\right)^{2}\right)<0$, this shows that the freshness of the product decreases with the increase in transportation time. $\left(\partial^{2}(e, t) / \partial t^{2}\right)=2 \alpha \beta e\left(3 \alpha t^{2}-1\right) /\left(1+\alpha t^{2}\right)^{3}$, while $t>$ $(1 / \sqrt{3 \alpha}),\left(\partial^{2} \theta(e, t) / \partial t^{2}\right)>0$; at this time, the rate of deterioration of fresh agricultural products is accelerating; that is, when the transportation time exceeds a certain threshold, 
TABLE 1: The main symbols used in the text.

\begin{tabular}{|c|c|}
\hline Symbol & Definition \\
\hline$p$ & Retailer unit product sales price \\
\hline$w$ & The unit product wholesale price provided by the supplier to the retailer \\
\hline$c$ & Supplier's unit product cost \\
\hline$e$ & The level of effort the supplier has made for the quality of fresh agricultural products $(e>0)$ \\
\hline$t$ & The time it takes for the supplier to transport the fresh produce to the retailer \\
\hline$\mu$ & Cost coefficient of preservation effort input $(0<\mu<1)$ \\
\hline$\varepsilon$ & Uncertainty of market demand ( $\varepsilon$ subject to normal distribution, expectation is 0 , variance is $\sigma^{2}$ ) \\
\hline$\alpha, \beta$ & They are the time-sensitive factor of freshness and the fresh-keeping effort sensitive factor, where $\alpha>0$ and $\beta>0$ \\
\hline$b, k$ & Respectively indicate the elasticity coefficient of market demand to price and freshness \\
\hline$\lambda$ & Retailer risk aversion coefficient \\
\hline
\end{tabular}

the rate of deterioration of the product will become faster and faster, which is consistent with the actual situation.

Assumption 4. In order to make the research results of this paper meaningful, suppose $2 b \mu-A^{2}>0$ and $a-b c>0$.

\section{Model Construction and Analysis}

4.1. Centralized Decision Model. In the centralized decisionmaking model, suppliers and retailers can be regarded as a whole, and their decision-making goal is to maximize the overall profit of the supply chain. Let $\pi$ denote the overall profit of the supply chain, and $U=E(\pi)$ denote the overall utility of the supply chain; then,

$$
\begin{aligned}
& \pi=(p-c)(a-b p+k \theta(e, t)+\varepsilon)-\frac{1}{2} \mu e^{2}, \\
& U=(p-c)(a-b p+k \theta(e, t))-\frac{1}{2} \mu e^{2} .
\end{aligned}
$$

Proposition 1. In the centralized decision-making model, the optimal effort level of the supplier is recorded as $e^{C *}$, the optimal selling price for fresh agricultural products is $p^{C *}$, and the maximum utility of the supply chain is $U^{C *}$; then,

$$
\begin{aligned}
e^{C *} & =\frac{A(a-b c)}{2 b \mu-A^{2}}, \\
p^{C *} & =\frac{\mu(a+b c)-A^{2} c}{2 b \mu-A^{2}}, \\
U^{C *} & =\frac{\mu(a-b c)^{2}}{2\left(2 b \mu-A^{2}\right)} .
\end{aligned}
$$

Among them, $A=\left(k \beta /\left(1+\alpha t^{2}\right)\right)$.

For the proof of Proposition 1, please see Appendix A.

4.2. Decentralized Decision Model. In the decentralized decision-making model, it is assumed that the supplier is risk-neutral, and the retailer is risk-averse, and a Stackelberg game is played between the two, and the retailer is in a dominant position during the game. Use $E\left(\pi_{r}\right)$, $\operatorname{Var}\left(\pi_{r}\right), U_{r}$ to represent the retailer's expected profit, profit variance, and mean-variance utility function. Among them,
$U_{r}=E\left(\pi_{r}\right)-\lambda \operatorname{Var}\left(\pi_{r}\right)$; here, $\lambda>0$ represents the degree of risk aversion of the retailer, and the larger the value, the more risk-averse the retailer.

$$
U_{r}=(p-c)(a-b p+k \theta(e, t))-\lambda \sigma^{2}(p-w)^{2} .
$$

Use $E\left(\pi_{s}\right), \operatorname{Var}\left(\pi_{s}\right), U_{s}$ to represent the supplier's profit expectation, variance, and mean-variance utility functions. Solve the optimal wholesale price and fresh-keeping technology level to maximize $U_{s}$. In this case, it can be expressed as follows:

$$
U_{s}=(w-c)(a-b p+k \theta(e, t))-\frac{1}{2} \mu e^{2} .
$$

Proposition 2. In the decentralized decision-making mode, record the supplier's optimal effort level as $e^{D *}$, the supplier's optimal wholesale price is $w^{D *}$, the optimal selling price of fresh agricultural products is $p^{D *}$, the retailer's utility is $U_{r}^{D *}$, and the supplier's utility is $U_{s}^{D *}$; then,

$$
\begin{aligned}
e^{D *} & =\frac{A\left(b+2 \lambda \sigma^{2}\right)(a-b c)}{4 b \mu\left(b+\lambda \sigma^{2}\right)-A^{2}\left(b+2 \lambda \sigma^{2}\right)} \\
w^{D *} & =\frac{2 \mu(a+b c)\left(b+\lambda \sigma^{2}\right)-A^{2} c\left(b+2 \lambda \sigma^{2}\right)}{4 b \mu\left(b+\lambda \sigma^{2}\right)-A^{2}\left(b+2 \lambda \sigma^{2}\right)}, \\
p^{D *} & =\frac{\mu(a+b c)\left(b+2 \lambda \sigma^{2}\right)+2 \mu a b-A^{2} c\left(b+2 \lambda \sigma^{2}\right)}{4 b \mu\left(b+\lambda \sigma^{2}\right)-A^{2}\left(b+2 \lambda \sigma^{2}\right)}, \\
U_{r}^{D *} & =\frac{b^{2} \mu^{2}(a-b c)^{2}\left(b+\lambda \sigma^{2}\right)}{\left[4 b \mu\left(b+\lambda \sigma^{2}\right)-A^{2}\left(b+2 \lambda \sigma^{2}\right)\right]^{2}} \\
U_{s}^{D *} & =\frac{\mu(a-b c)^{2}\left(b+2 \lambda \sigma^{2}\right)}{2\left[4 b \mu\left(b+\lambda \sigma^{2}\right)-A^{2}\left(b+2 \lambda \sigma^{2}\right)\right]^{2}} .
\end{aligned}
$$

The proof is in Appendix B.

Corollary 1. Under decentralized decision-making, the longer the transportation time $t$, the lower the supplier's wholesale price $w^{D *}$ and the lower the retailer's sales price $p^{D *}$. 
The proof is in Appendix C.

Corollary 2. Under decentralized decision-making, the supplier's optimal wholesale price $w^{D *}$ increases as the retailer's risk aversion degree increases; the supplier's optimal preservation effort level $e^{D *}$ increases with the retailer's risk aversion degree; when $b \mu<A^{2}<2 b \mu$, the retailer's optimal retail price $p^{D *}$ increased with the increase of its risk aversion. When $0<A^{2}<b \mu$, the retailer's optimal retail price $p^{D *}$ decreased with the increase of its risk aversion.

The proof is in Appendix D.

Corollary 3. Compared with centralized decision-making, under the decentralized decision-making model, the supplier's effort to keep fresh agricultural products decreases, and the effectiveness of the supply chain decreases.

The proof is in Appendix E.

\section{Coordination Contract}

5.1. Coordination Strategy under the Traditional Cost-Sharing Contract. In this section, the traditional cost-sharing contract is introduced to guide the supplier's fresh-keeping efforts under decentralized decision-making to reach the centralized decision-making level. The cost-sharing coordination mechanism is as follows: the retailer takes the $\varphi$ initiative to undertake the fresh-keeping effort level of the supplier, where $0<\varphi<1$. The retailer determines the market price of the product $p$, and the supplier determines the level of fresh-keeping effort $e$ and the unit product wholesale price $w$. Under the cost-sharing contract, the utility functions of retailers and supplier are

$$
\begin{aligned}
& U_{r}^{S}=(p-w)(a-b p+k \theta(e, t))-\lambda \sigma^{2}(p-w)^{2}-\frac{1}{2} \varphi \mu e^{2}, \\
& U_{s}^{S}=(w-c)(a-b p+k \theta(e, t))-\frac{1}{2}(1-\varphi) \mu e^{2} .
\end{aligned}
$$

Proposition 3. Traditional cost-sharing contracts cannot coordinate the supply chain.

The proof is in Appendix F.

5.2. Supply Chain Coordination Based on Revenue Sharing and Cost Sharing. It can be seen from the above that the traditional cost-sharing contract cannot achieve coordination of the supply chain. Therefore, in this section, the revenuesharing and cost-sharing contracts are designed to coordinate the supply chain in the decentralized mode to achieve the optimal decision in the centralized mode.

Assuming that the supplier charges the retailer the wholesale price at the cost of the product, that is, $w=c$, the retailer subsidizes the supplier with a proportion of $\eta(0<\eta<1)$, with the income as a return, while sharing the supplier's fresh-keeping effort with the cost proportion being $\varphi(0<\varphi<1)$, and then, the utility functions of the retailer and the supplier are, respectively,

$$
\begin{aligned}
U_{r}^{I}= & {[(1-\eta) p-c](a-b p+k \theta(e, t)) } \\
& -\lambda \sigma^{2}[(1-\eta) p-c]^{2}-\frac{1}{2} \mu \varphi e^{2}, \\
U_{s}^{I}= & \eta p(a-b p+k \theta(e, t))-\frac{1}{2} \mu(1-\varphi) e^{2} .
\end{aligned}
$$

Proposition 4. Cost-sharing and revenue-sharing contracts cannot make the supply chain coordinated.

The proof is in Appendix G.

5.3. Mixed Coordination Contract for Cost-Sharing and Compensation Strategies. Because the traditional costsharing contract, cost-sharing contract, and revenue-sharing contract cannot coordinate the supply chain, the hybrid contract of cost-sharing and compensation strategy is designed to coordinate the supply chain. In order to obtain lower wholesale prices and fresher products, the retailer takes the initiative to undertake the supplier's $\varphi$ part proportion of freshness preservation effort level, where $\varphi$ is from 0 to 1 . The retailer determines the retail price of the product $p$, and the supplier determines the preservation effort level $e$ and the wholesale price of the unit product $w$. Under the mixed coordination contract of cost-sharing and compensation strategy, the utility functions of retailers and supplier are as follows:

$$
\begin{aligned}
U_{r}^{T *}= & (p-w)(a-b p+k \theta(e, t)) \\
& -\lambda \sigma^{2}(p-w)^{2}-\frac{1}{2} \varphi \mu e^{2}-K \\
U_{s}^{T}= & (w-c)(a-b p+k \theta(e, t))-\frac{1}{2}(1-\varphi) \mu e^{2}+K .
\end{aligned}
$$

The wholesale price of the supplier is

$$
w^{T *}=\frac{2 \mu\left[b^{2} c+(a+b c) \lambda \sigma^{2}\right]-A^{2} \varphi \mu\left[\left(b+2 \lambda \sigma^{2}\right)^{2}\right]}{\left(2 b \mu-A^{2}\right)\left(b+2 \lambda \sigma^{2}\right)} .
$$

The utility of supplier and retailers can be calculated as follows:

$$
\begin{aligned}
& U_{r}^{T *}=\frac{(a-b c)^{2}\left[2 b^{2} \mu^{2}\left(b+\lambda \sigma^{2}\right)-A^{2} \varphi \mu\left(b+2 \lambda \sigma^{2}\right)^{2}\right]}{2\left(2 b \mu-A^{2}\right)^{2}\left(b+2 \lambda \sigma^{2}\right)^{2}}-K, \\
& U_{s}^{T *}=\frac{(a-b c)^{2}\left[4 b \mu^{2} \lambda \sigma^{2}-A^{2} \mu(1-\varphi)\left(b+2 \lambda \sigma^{2}\right)\right]}{2\left(2 b \mu-A^{2}\right)^{2}\left(b+2 \lambda \sigma^{2}\right)}+K .
\end{aligned}
$$


Proposition 5. Under the cost-sharing and compensation strategy hybrid coordination contract, when the compensation amount is $K \in\left(K_{1}, K_{2}\right)$, the supply chain can be coordinated. Among them,

$$
\begin{aligned}
& K_{1}=\frac{\left\{\mu\left(2 b \mu-A^{2}\right)^{2}\left(b+2 \lambda \sigma^{2}\right)^{2}-\left[4 b \mu^{2} \lambda \sigma^{2}-A^{2} \mu(1-\varphi)\left(b+2 \lambda \sigma^{2}\right)\right]\left[4 b \mu\left(b+\lambda \sigma^{2}\right)-A^{2}\left(b+2 \lambda \sigma^{2}\right)\right]\right\}(a-b c)^{2}}{2\left(2 b \mu-A^{2}\right)^{2}\left(b+2 \lambda \sigma^{2}\right)\left[4 b \mu\left(b+\lambda \sigma^{2}\right)-A^{2}\left(b+2 \lambda \sigma^{2}\right)\right]}, \\
& K_{2}=\frac{\left\{\left[2 b^{2} \mu^{2}\left(b+\lambda \sigma^{2}\right)-A^{2} \varphi \mu\left(b+2 \lambda \sigma^{2}\right)^{2}\right]\left[4 b \mu\left(b+\lambda \sigma^{2}\right)-A^{2}\left(b+2 \lambda \sigma^{2}\right)\right]^{2}-2 b^{2} \mu^{2}\left(b+\lambda \sigma^{2}\right)\left(2 b \mu-A^{2}\right)^{2}\left(b+2 \lambda \sigma^{2}\right)^{2}\right\}(a-b c)^{2}}{2\left(2 b \mu-A^{2}\right)^{2}\left(b+2 \lambda \sigma^{2}\right)^{2}\left[4 b \mu\left(b+\lambda \sigma^{2}\right)-A^{2}\left(b+2 \lambda \sigma^{2}\right)\right]^{2}} .
\end{aligned}
$$

The proof is in Appendix $H$.

\section{Numerical Simulation Analysis}

In this section, it is necessary to use mathematic software to do sensitivity analysis of the relevant parameters in the model proposed in this article, mainly analyzing the impact of transportation time, retailer's risk aversion coefficient, cost-sharing ratio, and compensation amount on decision variables. Assign values to the parameters in the model as follows:

$$
\begin{aligned}
& a=1000 \\
& b=50 \\
& c=8 \\
& \sigma=1.96 \\
& \mu=0.15 \\
& k=40 \\
& \alpha=0.08 \\
& \beta=0.15 \\
& t=10 \\
& \lambda=0.4 .
\end{aligned}
$$

6.1. The Effect of Time on Decision Variables. This section mainly discusses the impact of transportation time on the corresponding decision variables, mainly on the level of preservation efforts and the sales price of the product.

It can be seen from Figure 1 that, with the increase of transportation time, the fresh-keeping effort level gradually decreases under both centralized decision-making and decentralized decision-making. The fresh-keeping effort level under centralized decision-making is higher than decentralized decision-making. This is because fresh agricultural products have higher requirements for temperature, etc. As the transportation time increases, these conditions are gradually not met, the freshness of the products gradually decreases, and the level of fresh-keeping effort gradually decreases. Therefore, in order to maximize each other's interests, the transportation time should be shortened as much as possible, and the product preservation efforts should be increased to maximize the utility. Under centralized decision-making, decision-makers jointly make decisions that are beneficial to both parties, while, under decentralized decision-making, they make decisions that are beneficial to themselves. Therefore, the level of effort to preserve freshness is lower than decentralized decisionmaking.

It can be seen from Figure 2 that, with the increase of transportation time, the sales price of the product decreases under the decentralized decision, and the sales price of the product also decreases under the centralized decision. This is because, under the decentralized decision-making, the two sides of the game make decisions that are beneficial to them. As the transportation time increases, the level of preservation efforts gradually decreases. The supplier will not increase preservation costs in order to improve the level of preservation efforts, and product freshness decreases as consumer demand decreases, and the price of the product will drop. Under the centralized decision-making, as the transportation time increases, the freshness of the product decreases; this will reduce the sales price. The selling price under decentralized decision-making is higher than that under centralized decision-making; maybe it is caused by different motivations for making the decision. In decentralized decision-making, both parties are in their own interests. Therefore, the selling price is higher than that under centralized decision-making.

6.2. The Effect of Retailer's Risk Aversion Coefficient on Decision Variables. This section mainly discusses how each decision variable will change with the change of the retailer's risk aversion coefficient and then provide better decisionmaking for decision makers. The results are shown in figures 3 and 4 .

It can be seen from Figure 3 that as the retailer's risk aversion coefficient increases, the fresh-keeping effort level also increases. This is because the greater the risk aversion coefficient of a retailer, the more risk they avoid. Therefore, their decisions are insured. When buying fresh agricultural products, in order to avoid losses, they will choose products with high freshness. Therefore, in order to meet the needs of retailers, the supplier will increase its fresh-keeping efforts accordingly. Therefore, the fresh-keeping effort level has a positive relationship with the retailer's risk aversion coefficient. 


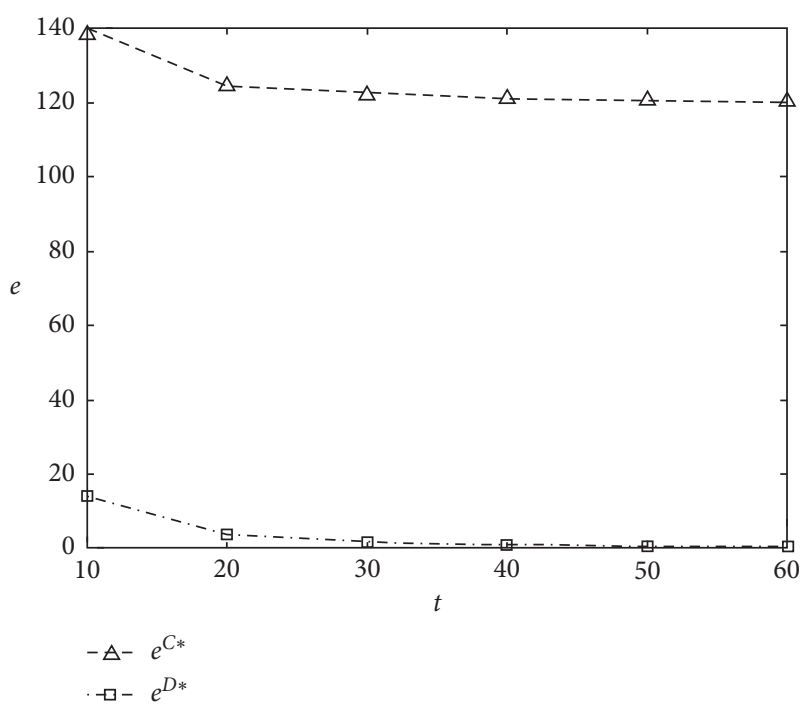

Figure 1: The effect of time on preservation effort.

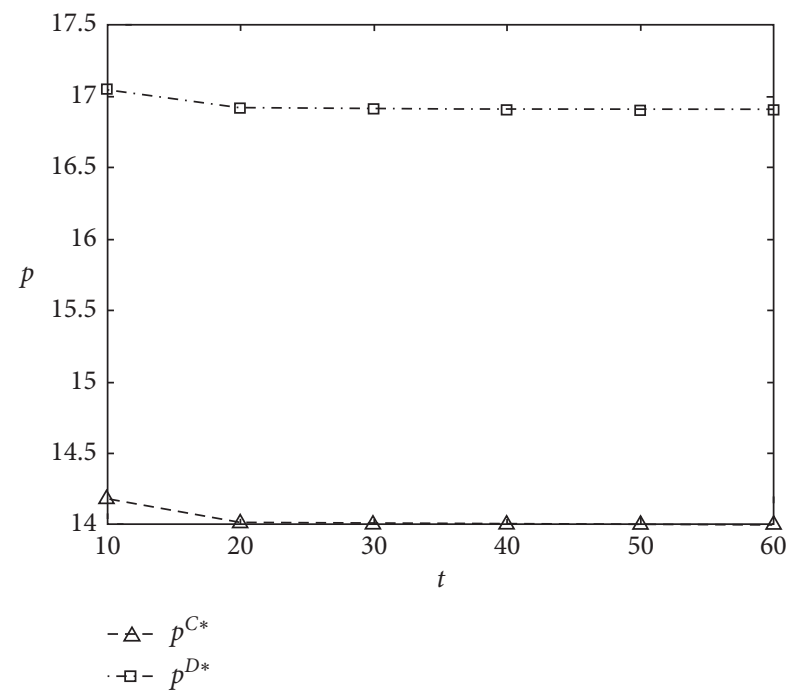

Figure 2: The effect of time on sales prices.

It can be seen from Figure 4 that the greater the retailer's risk aversion coefficient, the more risk-averse the retailer, and the higher the wholesale price. This is because the more the retailer avoids risks, the more they will choose fresh agricultural products with high freshness. In order to meet the needs of retailers, the supplier will correspondingly increase their own fresh-keeping efforts. The higher the fresh-keeping efforts, the more costly they are. Therefore, the wholesale price it provides to retailers also increases accordingly. Therefore, the wholesale price of fresh agricultural products has a positive relationship with the retailer's risk aversion coefficient.

In Figure 5, we can see that as the retailer's risk aversion coefficient increases, the more the retailer avoids risks, the lower the selling price of fresh agricultural products. This is because the more the retailer avoids risks, and the higher the

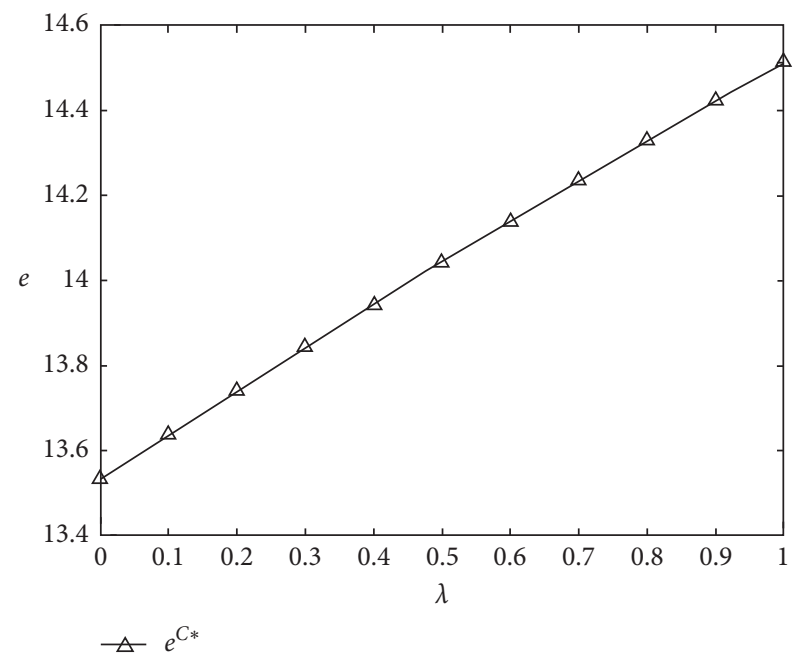

FIGURE 3: The effect of risk aversion coefficient on fresh-keeping effort.

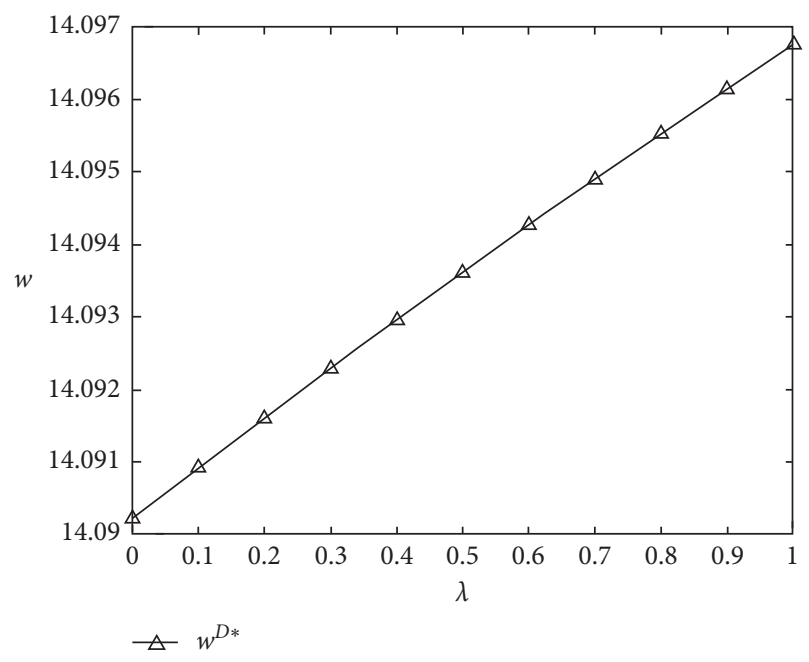

FIgURE 4: The effect of risk aversion coefficient on wholesale prices.

requirements for the freshness of fresh produce, the more the supplier will take measures to improve their preservation efforts, which will increase their cost. Therefore, in order to maximize their own interests, they will increase the wholesale price of the product accordingly, and the retailer's cost will increase accordingly, because the retailer is riskaverse, and they are more afraid of loss than profit. Therefore, in order to ensure the sale of products, the retailer will reduce the selling price of the product accordingly. Therefore, the retailer's sales price has a negative relationship with his risk aversion coefficient.

In Figure 6, we can see that as the retailer's risk aversion coefficient increases, the more the retailers avoid risks, the more the retailer's utility decreases, but the supplier's utility increases. This is because, as the retailer avoids risk more and more, we can see from Figures 3-5 that the fresh-keeping effort of supplier increases, the wholesale price of products 


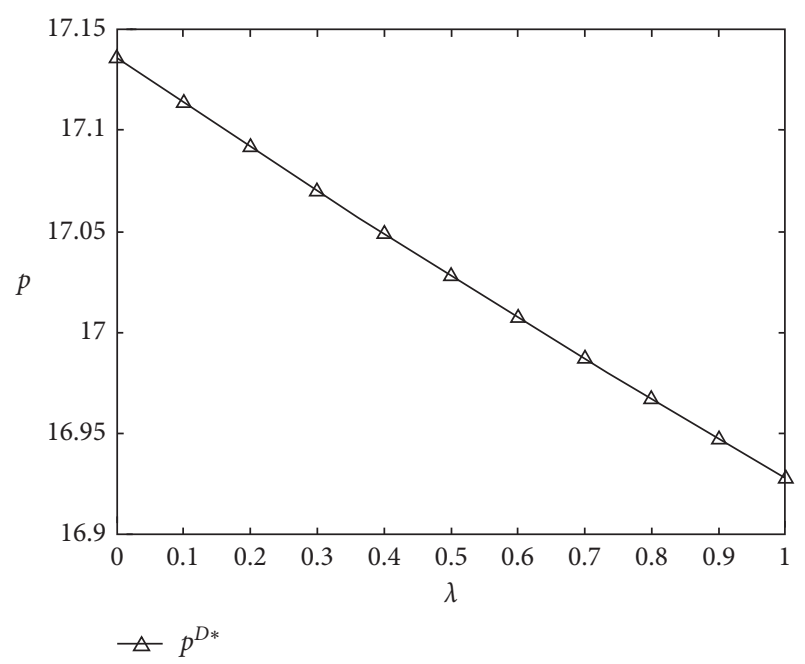

FIGURE 5: The effect of risk aversion coefficient on sales price.

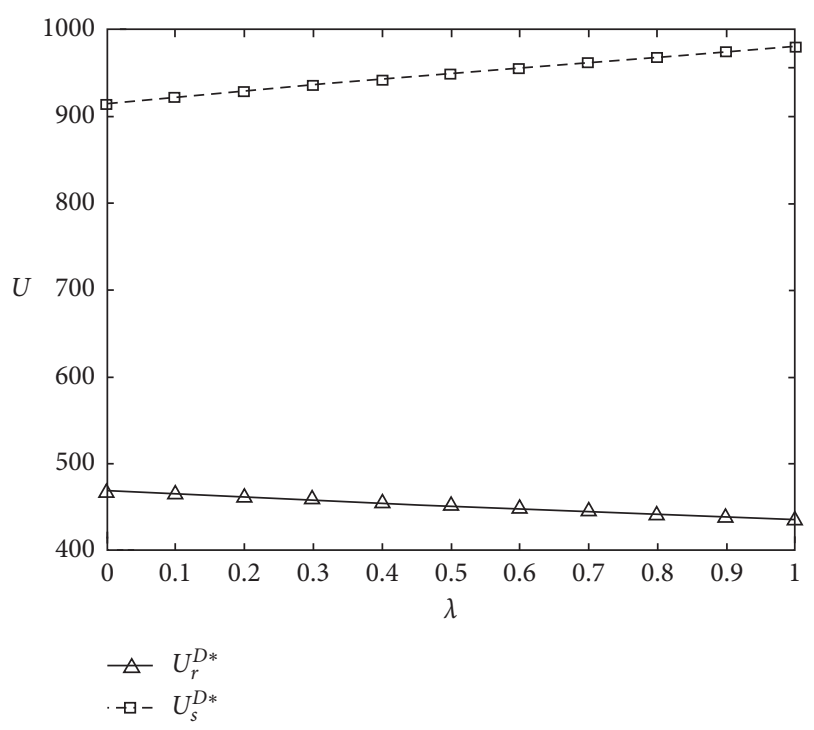

FIgURE 6: The effect of risk aversion coefficient on utility.

increases, the retailer's selling price decreases, and the retailer's utility decreases. With the increase in the wholesale prices, the utility of supplier has gradually increased.

6.3. The Effect of Cost-Sharing Ratio on Utility. This section mainly discusses how the utility of retailers and supplier will change when the cost-sharing ratio changes. At this time, the cost-sharing ratio $\varphi$ varies from 0 to 1 , and the compensation amount $K$ is 1000 . The result is shown in figures 7 and 8 .

It can be seen from Figure 7 that as the cost-sharing ratio increases, the retailer's utility gradually decreases. When the cost-sharing ratio exceeds a certain value, the retailer's utility is less than the utility under decentralized decision-making. Therefore, when the compensation amount is 1000, in order to coordinate the supply chain, the cost-sharing ratio must be less than a certain value. It can be seen from Figure 8 that as the retailer's cost-sharing ratio increases, the supplier's

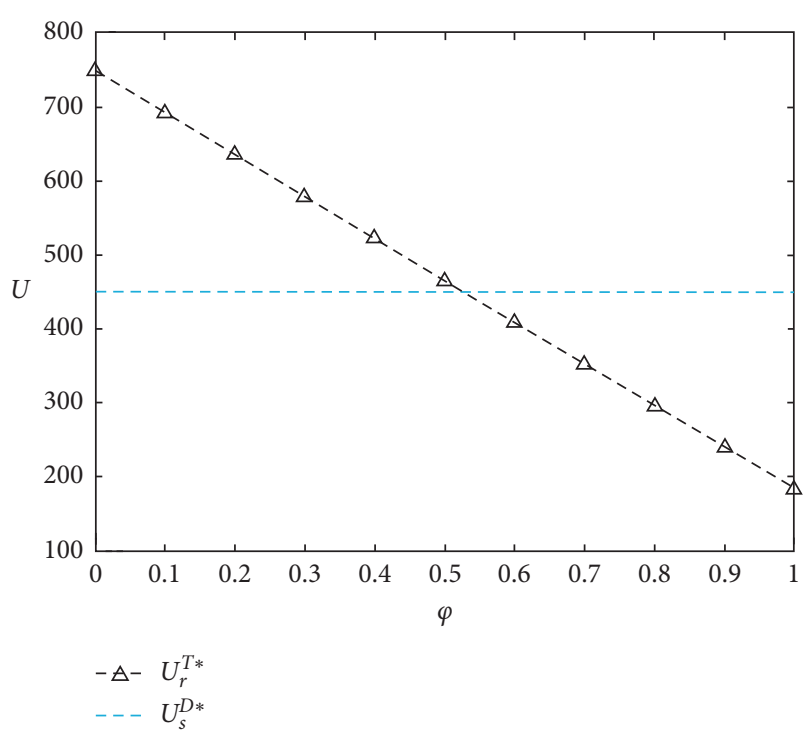

Figure 7: The effect of cost-sharing ratio on retailer utility.

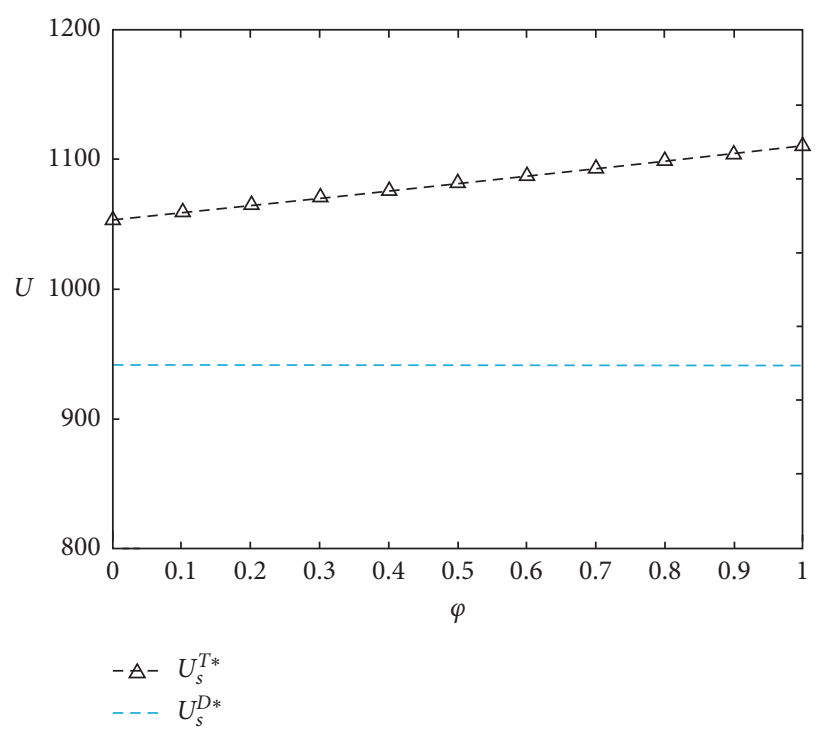

Figure 8: The effect of cost-sharing ratio on supplier utility.

utility gradually increases. Therefore, if the supplier wants to obtain more utility, it should encourage the retailer to bear as much cost as possible.

6.4. The Effect of Compensation on Utility. This section mainly discusses how the utility of retailers and supplier will change when the amount of compensation changes. At this time, the compensation amount $K$ varies from 700 to 1200 , and the cost-sharing ratio is 0.4 . The result is shown in figures 9 and 10.

It can be seen from Figure 9 that as the amount of compensation increases, the retailer's utility gradually decreases and then becomes smaller than the decentralized decision-making. In order to achieve coordination, it should 


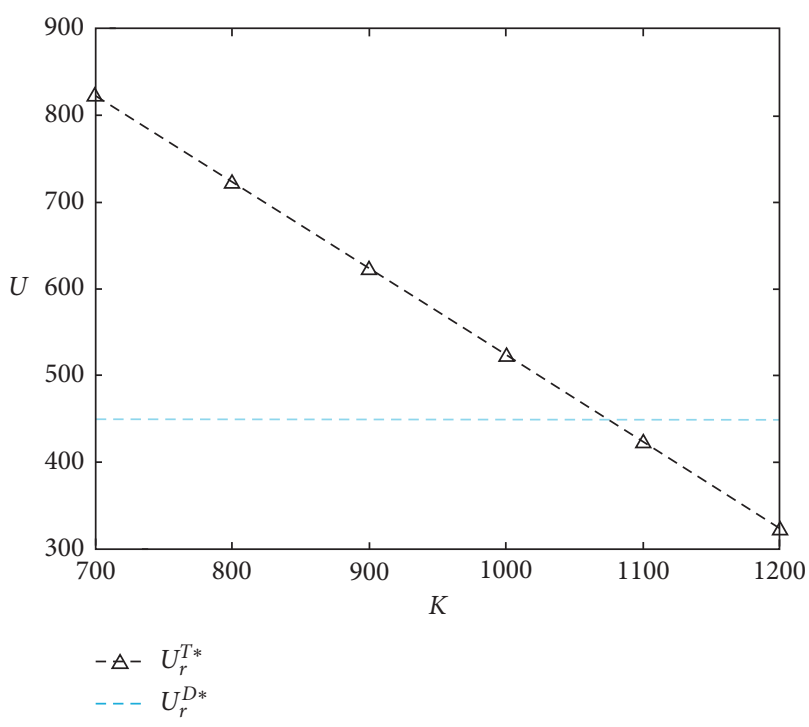

FIgURE 9: The effect of compensation on retailer utility.

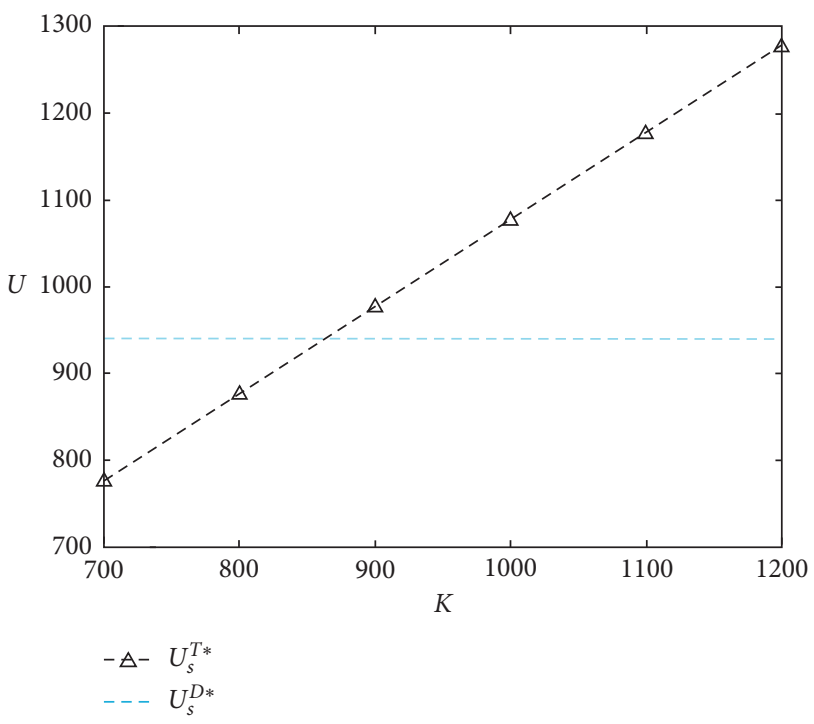

FIGURE 10: The effect of compensation on supplier utility.

be ensured that the amount of compensation is not greater than a certain value, as can be seen in Figure 10. As the compensation amount increases, the supplier's utility gradually increases, and when the compensation amount is greater than a certain value, it is greater than the utility under decentralized decision-making. Therefore, in order to achieve coordination, it is necessary to ensure that the compensation amount is not less than a certain value. In order to make the decision-making parties to accept this coordination contract, the compensation amount should be kept within a certain range, and the amount of compensation depends on the bargaining power of the retailer and the supplier.

\section{Conclusion}

In this paper, the freshness of products is characterized by the level of fresh-keeping effort and time factors, and the impact of fresh-keeping effort and price on demand is considered to construct a two-level fresh produce supply chain model composed of a risk-neutral supplier and a riskaverse retailer. The model obtains the optimal decisions of decision makers in centralized and decentralized situations. This paper designs the traditional cost-sharing contract, cost-sharing and revenue-sharing contract, and mixed contract of cost-sharing and compensation strategy to coordinate the supply chain. The results of this paper show the following: (1) with the increase of transportation time, the freshness preservation effort of the supplier will be reduced, and the selling price of the product will also be reduced in both the centralized and decentralized decision-making cases. (2) In the case of decentralized decision-making, the retailer' risk-averse characteristic will prompt the supplier to improve his fresh-keeping efforts and also lead to higher wholesale price of products. And with the increase of risk aversion of the retailer, the selling price of the product and the profit of the retailer will decrease, while the profit of the supplier will increase. (3) The traditional cost-sharing contract and cost-sharing and revenue-sharing contracts cannot make the supply chain coordinated. Under the mixed contract of cost-sharing and compensation strategies, when the compensation amount meets certain conditions, the supply chain can achieve perfect coordination, and the compensation amount is determined by the bargaining power of both parties.

From the research, we can reach some managerial insights. First, it is extremely necessary for the supplier to reduce transport times of fresh produce; long time transportation will reduce the freshness of fresh agricultural products, which will affect their sales price. Second, retailer's risk-averse behavior will motivate the supplier to improve the freshness level of his products, but excessive focus on risk will reduce the profits of the retailer. Third, reasonable compensation mechanism can encourage supply chain members to make decisions from the perspective of overall optimal, so as to maximize the overall benefits of supply chain and improve the benefits of both suppliers and retailers.

This article also has certain shortcomings. For example, when constructing the model, it only considers a supply chain composed of a risk-neutral supplier and risk-averse retailers but does not consider the supplier's risk attitude. Further researches can be conducted from this perspective in the future. And this paper only analyzes the decision-making and optimization problems of the two-level supply chain, which is 
far more complicated in real life and involves multilevel supply chains. Therefore, the situation of multilevel supply chains should also be considered in future research.

\section{Appendix}

\section{A. Proof of Proposition 1}

For equation (1) about $e$ and $p$, find the first derivative, and set the first derivative to 0 , and the simultaneous equations solve the optimal solution.

Solve

$$
\begin{aligned}
& \frac{\partial U}{\partial p}=-2 b p+(a+e A+b c), \\
& \frac{\partial U}{\partial e}=A(p-c)-\mu e .
\end{aligned}
$$

Let $(\partial U / \partial p)=0,(\partial U / \partial e)=0$, and get

$$
\begin{aligned}
e & =\frac{A(p-c)}{\mu}, \\
p^{C *} & =\frac{(a+b c) \mu-A^{2} c}{2 b \mu-A^{2}} .
\end{aligned}
$$

Substituting $\quad p^{C *}=\left((a+b c) \mu-A^{2} c\right) /\left(2 b \mu-A^{2}\right)$ into $\partial U / \partial e=0$, get

$$
A\left(\frac{(a+b c) \mu-A^{2} c}{2 b \mu-A^{2}}-c\right)-\mu e=0 .
$$

Solve

$$
e^{C *}=\frac{A(a-b c)}{2 b \mu-A^{2}} .
$$

Substituting $p^{C *}, e^{C *}$ into equation (1), hence, we have the optimal utility as follows:

$$
\begin{aligned}
U^{C *}= & \left(\frac{(a+b c) \mu-A^{2} c}{2 b \mu-A^{2}}-\frac{c\left(2 b \mu-A^{2}\right)}{2 b \mu-A^{2}}\right) \\
& \cdot\left(\frac{a\left(2 b \mu-A^{2}\right)-b(a+b c) \mu+A^{2} b c+A^{2}(a-b c)}{2 b \mu-A^{2}}\right) \\
& -\frac{\mu A^{2}(a-b c)^{2}}{2\left(2 b \mu-A^{2}\right)^{2}} \\
= & \frac{b \mu^{2}(a-b c)^{2}}{\left(2 b \mu-A^{2}\right)^{2}}-\frac{\mu A^{2}(a-b c)^{2}}{2\left(2 b \mu-A^{2}\right)^{2}} \\
= & \frac{\mu(a-b c)^{2}}{2\left(2 b \mu-A^{2}\right)^{2}} .
\end{aligned}
$$

\section{B. Proof of Proposition 2}

Find the first derivative with respect to equation (3) and set the first derivative to 0 . We can get

$$
U_{r}=a p-b p^{2}+e A p-w a+w b p-w e A-\lambda \sigma^{2}(p-w)^{2}
$$

$$
\begin{aligned}
\frac{\partial U_{r}}{\partial p}= & -2 b p+(a+e A+w b) \\
& -2 \lambda \sigma^{2}(p-w) \frac{\partial U_{r}}{\partial p}=0, p=\frac{a+e A+\left(b+2 \lambda \sigma^{2}\right) w}{2\left(b+\lambda \sigma^{2}\right)}
\end{aligned}
$$

Substitute $p$ into formula (4), we can get

$$
U_{s}=\frac{(w-c)\left(b+2 \lambda \sigma^{2}\right)(a+e A-b w)}{2\left(b+\lambda \sigma^{2}\right)}-\frac{1}{2} \mu e^{2},
$$

$$
\begin{aligned}
& \frac{\partial U_{s}}{\partial w}=\frac{\left(b+2 \lambda \sigma^{2}\right)(b c+a)}{2\left(b+\lambda \sigma^{2}\right)}+\frac{A\left(b+2 \lambda \sigma^{2}\right)}{2\left(b+\lambda \sigma^{2}\right)} e-\frac{b\left(b+2 \lambda \sigma^{2}\right)}{b+\lambda \sigma^{2}} w, \\
& \frac{\partial U_{s}}{\partial e}=\frac{A\left(b+2 \lambda \sigma^{2}\right)}{2\left(b+\lambda \sigma^{2}\right)} w-\frac{A c\left(b+2 \lambda \sigma^{2}\right)}{2\left(b+\lambda \sigma^{2}\right)}-\mu e .
\end{aligned}
$$

Calculate the partial derivatives of the product wholesale price and the fresh-keeping effort level of equation (5), respectively, to obtain the second-order Hessian matrix:

$$
H=\left[\begin{array}{cc}
-\frac{b\left(b+2 \lambda \sigma^{2}\right)}{b+\lambda \sigma^{2}} & \frac{A\left(b+2 \lambda \sigma^{2}\right)}{2\left(b+\lambda \sigma^{2}\right)} \\
\frac{A\left(b+2 \lambda \sigma^{2}\right)}{2\left(b+\lambda \sigma^{2}\right)} & -\mu
\end{array}\right] .
$$

When $\left(A^{2}\left(b+2 \lambda \sigma^{2}\right) / b \mu\left(b+\lambda \sigma^{2}\right)\right)<4$, it is negative definite; that is, the utility of the supplier $U_{s}$ is a concave function of the product wholesale price $w$ and the preservation effort level $e$.

Let

$$
\begin{aligned}
& \frac{\left(b+2 \lambda \sigma^{2}\right)(b c+a)}{2\left(b+\lambda \sigma^{2}\right)}+\frac{A\left(b+2 \lambda \sigma^{2}\right)}{2\left(b+\lambda \sigma^{2}\right)} e-\frac{b\left(b+2 \lambda \sigma^{2}\right)}{b+\lambda \sigma^{2}} w=0, \\
& \frac{A\left(b+2 \lambda \sigma^{2}\right)}{2\left(b+\lambda \sigma^{2}\right)} w-\frac{A c\left(b+2 \lambda \sigma^{2}\right)}{2\left(b+\lambda \sigma^{2}\right)}-\mu e=0 .
\end{aligned}
$$

Simultaneous equation (B.4) can be obtained from (B.4):

$$
e=\frac{A\left(b+2 \lambda \sigma^{2}\right)}{2 \mu\left(b+\lambda \sigma^{2}\right)} w-\frac{A c\left(b+2 \lambda \sigma^{2}\right)}{2 \mu\left(b+\lambda \sigma^{2}\right)} .
$$

Substituting $e$ into (B.4), we can get 


$$
\frac{\left(b+2 \lambda \sigma^{2}\right)[b c+a]}{2\left(b+\lambda \sigma^{2}\right)}+\frac{A\left(b+2 \lambda \sigma^{2}\right)}{2\left(b+\lambda \sigma^{2}\right)}\left[\frac{A\left(b+2 \lambda \sigma^{2}\right)}{2 \mu\left(b+\lambda \sigma^{2}\right)} w-\frac{A c\left(b+2 \lambda \sigma^{2}\right)}{2 \mu\left(b+\lambda \sigma^{2}\right)}\right]-\frac{b\left(b+2 \lambda \sigma^{2}\right)}{b+\lambda \sigma^{2}} w=0 .
$$

Then,

$$
w^{D *}=\frac{2 \mu\left(b+\lambda \sigma^{2}\right)(b c+a)-A^{2} c\left(b+2 \lambda \sigma^{2}\right)}{4 b \mu\left(b+\lambda \sigma^{2}\right)-A^{2}\left(b+2 \lambda \sigma^{2}\right)} .
$$

Substitute $w^{D *}$ into

$$
\begin{aligned}
e^{D *}= & \frac{2 \mu A\left(b+2 \lambda \sigma^{2}\right)\left(b+\lambda \sigma^{2}\right)(b c+a)-A^{2} c\left(b+2 \lambda \sigma^{2}\right)}{2 \mu\left(b+\lambda \sigma^{2}\right)\left[4 b \mu\left(b+\lambda \sigma^{2}\right)-A^{2}\left(b+2 \lambda \sigma^{2}\right)\right]} \\
& -\frac{A c\left(b+2 \lambda \sigma^{2}\right)}{2 \mu\left(b+\lambda \sigma^{2}\right)} .
\end{aligned}
$$

And then substitute the obtained $w^{D *}, e^{D *}$ into

$$
p=\frac{a+e A+\left(b+2 \lambda \sigma^{2}\right) w}{2\left(b+\lambda \sigma^{2}\right)} \text {. }
$$

We can get

$$
p^{D *}=\frac{\mu(a+b c)\left(b+2 \lambda \sigma^{2}\right)+2 \mu a b-A^{2} c\left(b+2 \lambda \sigma^{2}\right)}{4 \mu b\left(b+\lambda \sigma^{2}\right)-A^{2}\left(b+2 \lambda \sigma^{2}\right)} .
$$

Then, substituting $w^{D *}, e^{D *}, p^{D *}$ into equations (3) and (4), we can get

$$
\begin{aligned}
& U_{r}^{D *}=\frac{b^{2} \mu^{2}(a-b c)^{2}\left(b+\lambda \sigma^{2}\right)}{\left[4 \mu b\left(b+\lambda \sigma^{2}\right)-A^{2}\left(b+2 \lambda \sigma^{2}\right)\right]^{2}}, \\
& U_{s}^{D *}=\frac{\mu(a-b c)^{2}\left(b+2 \lambda \sigma^{2}\right)}{2\left[4 \mu b\left(b+\lambda \sigma^{2}\right)-A^{2}\left(b+2 \lambda \sigma^{2}\right)\right]} .
\end{aligned}
$$

\section{Proof of Corollary 1}

Derivation of $w^{D *}$ and $p^{D *}$ with respect to time:

$$
\begin{aligned}
& \frac{\partial w^{D *}}{\partial t}=\frac{8 \mu \alpha t A^{2}\left(b+2 \lambda \sigma^{2}\right)\left(b+\lambda \sigma^{2}\right)(b c-a)}{\left[4 b \mu\left(b+\lambda \sigma^{2}\right)-A^{2}\left(b+2 \lambda \sigma^{2}\right)\right]^{2}\left(1+\alpha t^{2}\right)}, \\
& \frac{\partial p^{D *}}{\partial t}=\frac{4 A^{2} \mu\left(b+2 \lambda \sigma^{2}\right)\left(3 b+2 \lambda \sigma^{2}\right)(b c-a)}{\left[4 b \mu\left(b+\lambda \sigma^{2}\right)-A^{2}\left(b+2 \lambda \sigma^{2}\right)\right]^{2}\left(1+\alpha t^{2}\right)} \alpha t .
\end{aligned}
$$

Because $e^{D *}>0$, then $a-b c>0$ since $\left(\partial w^{D *} / \partial t\right)<0$. That is, the wholesale price provided by the supplier to the retailer decreases as the transportation time $t$ increases. This is because as the transportation time $t$ increases, product freshness decreases, and customer demand decreases. In order to maximize their utility, retailers will choose supplier with lower wholesale prices. In the same way, since $\left(\partial p^{D *} / \partial t\right)<0$, the retailer's sales price decreases with the increase of the transportation time. As the transportation time increases, the freshness of fresh agricultural products gradually decreases, and the demand of customers will also decrease. Therefore, its sales price decreases.

\section{Proof of Corollary 2}

Derivation $w^{D *}, e^{D *}, p^{D *}$ of the retailer's risk aversion coefficient:

$$
\begin{aligned}
& \frac{\partial w^{D *}}{\partial \lambda}=\frac{2 b \mu A^{2} \sigma^{2}(a-b c)}{\left[A^{2}\left(b+2 \lambda \sigma^{2}\right)-4 b \mu\left(b+\lambda \sigma^{2}\right)\right]^{2}}, \\
& \frac{\partial w^{e *}}{\partial \lambda}=\frac{4 A b^{2} \sigma^{2} \mu(a-b c)}{\left[A^{2}\left(b+2 \lambda \sigma^{2}\right)-4 b \mu\left(b+\lambda \sigma^{2}\right)\right]^{2}}, \\
& \frac{\partial p^{D *}}{\partial \lambda}=\frac{4 b \mu \lambda \sigma^{2}\left(A^{2}-b \mu\right)(a-b c)}{\left[A^{2}\left(b+2 \lambda \sigma^{2}\right)-4 b \mu\left(b+\lambda \sigma^{2}\right)\right]^{2}} .
\end{aligned}
$$

Since $a-b c>0,\left(\partial w^{D *} / \partial \lambda\right)>0$, the supplier's optimal wholesale price $w^{D *}$ increases as the retailer's risk aversion degree increases. It can be proved by the same reason, $\left(\partial e^{D *} / \partial \lambda\right)>0$, that the supplier's optimal preservation effort level $e^{D *}$ increases with the retailer's degree of risk aversion. Since $b \mu<A^{2}<2 b \mu,\left(\partial p^{D *} / \partial \lambda\right)>0$, the retailer's optimal retail price $p^{D *}$ increases as its risk aversion degree increases. Since $0<A^{2}<b \mu,\left(\partial p^{D *} / \partial \lambda\right)<0$, the retailer's optimal retail price $p^{D *}$ decreases as its risk aversion degree increases. The certificate is complete.

\section{E. Proof of Corollary 3}

Under the centralized and decentralized decision-making mode, the difference between the supplier' fresh-keeping efforts is 


$$
\begin{aligned}
e^{C *}-e^{D *} & =\frac{2 A b^{2} \mu(a-b c)}{\left(2 b \mu-A^{2}\right)\left[4 b \mu\left(b+\lambda \sigma^{2}\right)-A^{2}\left(b+2 \lambda \sigma^{2}\right)\right]}, \\
a-b c & >0, \\
2 b \mu-A^{2} & >0, \\
4 b \mu\left(b+\lambda \sigma^{2}\right)-A^{2}\left(b+2 \lambda \sigma^{2}\right)>\left(2 b \mu-A^{2}\right)\left(b+2 \lambda \sigma^{2}\right) & >0 .
\end{aligned}
$$

Then, $e^{C *}-e^{D *}>0, e^{C *}>e^{D *}$.

That is, the decentralized decision-making model reduces the supplier's fresh-keeping effort.

$$
\begin{aligned}
U^{C *}-U_{s}^{D *}-U_{s}^{D *}= & \frac{\mu(a-b c)^{2}}{2\left(2 b \mu-A^{2}\right)}-\frac{b^{2} \mu^{2}(a-b c)^{2}\left(b+\lambda \sigma^{2}\right)}{\left[4 b \mu\left(b+\lambda \sigma^{2}\right)-A^{2}\left(b+2 \lambda \sigma^{2}\right)\right]^{2}} \\
& -\frac{\mu(a-b c)^{2}\left(b+2 \lambda \sigma^{2}\right)}{2\left[4 b \mu\left(b+\lambda \sigma^{2}\right)-A^{2}\left(b+2 \lambda \sigma^{2}\right)\right]}=\frac{2 b^{2} \mu^{2}(a-b c)^{2}\left[2 b^{2} \mu+\lambda \sigma^{2}\left(2 b \mu-A^{2}\right)\right]}{2\left(2 b \mu-A^{2}\right)\left[4 b \mu\left(b+\lambda \sigma^{2}\right)-A^{2}\left(b+2 \lambda \sigma^{2}\right)\right]^{2}}
\end{aligned}
$$

Since $2 b \mu-A^{2}>0$, then $U^{C *}-U_{\mathrm{r}}^{\mathrm{D} *}-U_{s}^{D *}>0$.

That is, the overall utility of the centralized decision model is greater than that of the decentralized decision model.

\section{F. Proof of Proposition 3}

Taking the derivative of (6) with respect to $p$ and setting the derivative to 0 , we can get

$$
p=\frac{a+e A+w\left(b+2 \lambda \sigma^{2}\right)}{2\left(b+\lambda \sigma^{2}\right)} .
$$

Substituting $p$ into equation (6) and finding the first derivative with respect to $e, w$, and setting it to 0 , we can get

$$
\begin{aligned}
e^{S *} & =\frac{A(a-b c)\left(b+2 \lambda \sigma^{2}\right)}{4 b \mu(1-\varphi)\left(b+\lambda \sigma^{2}\right)-A^{2}\left(b+2 \lambda \sigma^{2}\right)} \\
\omega^{S *} & =\frac{2 \mu(1-\varphi)\left(b+\lambda \sigma^{2}\right)(a+b c)-A^{2} c\left(b+2 \lambda \sigma^{2}\right)}{4 b \mu(1-\varphi)\left(b+\lambda \sigma^{2}\right)-A^{2}\left(b+2 \lambda \sigma^{2}\right)}
\end{aligned}
$$

Substituting $e^{S *}, w^{S *}$ into $p$, we can get

$$
p^{S *}=\frac{\mu(1-\varphi)\left[2 a b+(a+b c)\left(b+2 \lambda \sigma^{2}\right)\right]-A^{2} c\left(b+2 \lambda \sigma^{2}\right)}{4 b \mu(1-\varphi)\left(b+\lambda \sigma^{2}\right)-A^{2}\left(b+2 \lambda \sigma^{2}\right)} .
$$

In order to coordinate the supply chain, it should meet $p^{S *}=p^{C *}, e^{S *}=e^{C *}, \quad$ from $\quad e^{S *}=e^{C *} \quad$ get $\phi_{1}=\left(b /\left(2\left(b+\lambda \sigma^{2}\right)\right)\right), \quad$ from $\quad p^{S *}=p^{C *} \quad$ get $\phi_{2}=\left(\left(2 b\left(A^{2}-b \mu\right)\right) /\left(3 A^{2} b-2 A^{2} \lambda \sigma^{2}-2 b^{2} \mu\right)\right)$.

Because $\phi_{1} \neq \phi_{2}$, the traditional cost-sharing contract cannot coordinate the supply chain.

\section{G. Proof of Proposition 4}

Take the derivative of $U_{r}^{I}$ about $p$ and set the derivative to 0 to get

$$
p=\frac{b c+(1-\eta)\left(a+e A+2 c \lambda \sigma^{2}\right)}{2(1-\eta)\left[b+(1-\eta) \lambda \sigma^{2}\right]}
$$

Substitute $p$ into equation (7) and find the first derivative of equation (7) with respect to $e$ and set its derivative to 0 to obtain

$$
e^{I *}=\frac{A \eta\left(a+c \lambda \sigma^{2}\right)\left[b+2(1-\eta) \lambda \sigma^{2}\right]}{2 \mu(1-\phi)\left[b+(1-\eta) \lambda \sigma^{2}\right]-A^{2} \eta\left[b+2(1-\eta) \lambda \sigma^{2}\right]} .
$$


Substituting $e^{I *}$ into $p$, you can get

$$
p^{I *}=\frac{2 \mu(1-\phi)\left[b c+(1-\eta)\left(a+2 c \lambda \sigma^{2}\right)\right]-A^{2} c \eta\left[b+2(1-\eta) \lambda \sigma^{2}\right]}{4 \mu(1-\phi)(1-\eta)\left[b+(1-\eta) \lambda \sigma^{2}\right]-2 A^{2} \eta(1-\eta)\left[b+2(1-\eta) \lambda \sigma^{2}\right]} .
$$

In order to be able to coordinate the supply chain, it

And the following can be obtained: should meet $e^{I *}=e^{C *}, p^{I *}=p^{C *}$.

$$
\begin{aligned}
c_{1}= & \frac{2 A a \mu(1-\phi)\left[b+(1-\eta) \lambda \sigma^{2}\right]-\left[A^{3} a \eta+A a \eta\left(2 b \mu-A^{2}\right)\right]\left[b+2(1-\eta) \lambda \sigma^{2}\right]}{\left[A \eta \lambda \sigma^{2}\left(2 b \mu-A^{2}\right)-A^{3} b \eta\right]\left[b+2(1-\eta) \lambda \sigma^{2}\right]+2 A b \mu(1-\phi)\left[b+(1-\eta) \lambda \sigma^{2}\right]}, \\
c_{2}= & \frac{4 a \mu^{2}(1-\varphi)(1-\eta)\left[b+(1-\eta) \lambda \sigma^{2}\right]-2 A^{2} a \mu \eta(1-\eta)\left[b+2(1-\eta) \lambda \sigma^{2}\right]}{\left[A^{2} \eta\left(3 A^{2}-2 A^{2} \eta-2 b \mu \eta\right)+2 \mu(1-\varphi)\left(2 b \mu-A^{2}\right)\right]\left[b+2(1-\eta) \lambda \sigma^{2}\right]-4 \mu(1-\varphi)(1-\eta)\left(A^{2}+b \mu\right)\left[b+(1-\eta) \lambda \sigma^{2}\right]}, \\
& -\frac{2 a \mu(1-\varphi)(1-\eta)\left(2 b \mu-A^{2}\right)}{\left[A^{2} \eta\left(3 A^{2}-2 A^{2} \eta-2 b \mu \eta\right)+2 \mu(1-\varphi)\left(2 b \mu-A^{2}\right)\right]\left[b+2(1-\eta) \lambda \sigma^{2}\right]-4 \mu(1-\varphi)(1-\eta)\left(A^{2}+b \mu\right)\left[b+(1-\eta) \lambda \sigma^{2}\right]} .
\end{aligned}
$$

In order to coordinate the supply chain, it should satisfy $c_{1}=c_{2}$. Then, the revenue-sharing ratio and cost-sharing ratio should satisfy the relationship

$$
\begin{aligned}
& {\left[b+(1-\eta) \lambda \sigma^{2}\right]\left[b+2(1-\eta) \lambda \sigma^{2}\right]+\left\{A^{2} \eta^{2}(1-\eta)\left[\lambda \sigma^{2}\left(2 b \mu-A^{2}\right)-3 A^{2} b\right]+\left(2 b \mu-A^{2}\right)\left[A^{2} b \eta^{2}-2 b \mu \eta(1-\varphi)\right]\right\}} \\
& {\left[b+2(1-\eta) \lambda \sigma^{2}\right]^{2}-4 \mu(1-\varphi)^{2}(1-\eta)\left(A^{2}+2 b \mu\right)\left[b+(1-\eta) \lambda \sigma^{2}\right]^{2}+\eta(1-\varphi)(1-\eta)\left(2 b \mu-A^{2}\right)} \\
& {\left[A^{2} b-\left(2 b \mu-A^{2}\right) \lambda \sigma^{2}\right]\left[b+2(1-\eta) \lambda \sigma^{2}\right]-2 b \mu(1-\varphi)^{2}(1-\eta)\left(2 b \mu-A^{2}\right)\left[b+(1-\eta) \lambda \sigma^{2}\right]=0 .}
\end{aligned}
$$

It is impossible to find the value of the cost-sharing ratio $\varphi$ and the revenue-sharing ratio $\eta$. Therefore, the costsharing and revenue-sharing contracts cannot make the supply chain coordinated.

\section{H. Proof of Proposition 5}

Proof. Take the derivative of $U_{r}^{T}$ about $p$ and set the derivative to 0 to get

$$
p=\frac{a+e A+w\left(b+2 \lambda \sigma^{2}\right)}{2\left(b+\lambda \sigma^{2}\right)}
$$

Let $p=p^{C *}, e=e^{C *}$, and get

$$
w^{T *}=\frac{2 \mu\left[b^{2} c+(a+b c) \lambda \sigma^{2}\right]-A^{2} \varphi \mu\left[\left(b+2 \lambda \sigma^{2}\right)^{2}\right]}{\left(2 b \mu-A^{2}\right)\left(b+2 \lambda \sigma^{2}\right)} .
$$

Substitute $w^{T *}, p^{T *}, e^{T *}$ into $U_{r}^{T}, U_{s}^{T}$ $U_{r}^{T *}=\frac{(a-b c)^{2}\left[2 b^{2} \mu^{2}\left(b+\lambda \sigma^{2}\right)-A^{2} \varphi \mu\left(b+2 \lambda \sigma^{2}\right)^{2}\right]}{2\left(2 b \mu-A^{2}\right)^{2}\left(b+2 \lambda \sigma^{2}\right)^{2}}-K$, $U_{s}^{T *}=\frac{(a-b c)^{2}\left[4 b \mu^{2} \lambda \sigma^{2}-A^{2} \mu(1-\varphi)\left(b+2 \lambda \sigma^{2}\right)\right]}{2\left(2 b \mu-A^{2}\right)^{2}\left(b+2 \lambda \sigma^{2}\right)}+K$. 
In order for the hybrid contract to be effective, it should satisfy $U_{r}^{T *}-U_{r}^{D *} \geq 0, U_{s}^{T *}-U_{s}^{D *} \geq 0$, and we can get

$$
\begin{aligned}
& K_{1} \leq K \leq K_{2} \\
& K_{1}=\frac{\left\{\mu\left(2 b \mu-A^{2}\right)^{2}\left(b+2 \lambda \sigma^{2}\right)^{2}-\left[4 b \mu^{2} \lambda \sigma^{2}-A^{2} \mu(1-\varphi)\left(b+2 \lambda \sigma^{2}\right)\right]\left[4 b \mu\left(b+\lambda \sigma^{2}\right)-A^{2}\left(b+2 \lambda \sigma^{2}\right)\right]\right\}(a-b c)^{2}}{2\left(2 b \mu-A^{2}\right)^{2}\left(b+2 \lambda \sigma^{2}\right)\left[4 b \mu\left(b+\lambda \sigma^{2}\right)-A^{2}\left(b+2 \lambda \sigma^{2}\right)\right]}, \\
& K_{2}=\frac{\left\{\left[2 b^{2} \mu^{2}\left(b+\lambda \sigma^{2}\right)-A^{2} \varphi \mu\left(b+2 \lambda \sigma^{2}\right)^{2}\right]\left[4 b \mu\left(b+\lambda \sigma^{2}\right)-A^{2}\left(b+2 \lambda \sigma^{2}\right)\right]^{2}-2 b^{2} \mu^{2}\left(b+\lambda \sigma^{2}\right)\left(2 b \mu-A^{2}\right)^{2}\left(b+2 \lambda \sigma^{2}\right)^{2}\right\}(a-b c)^{2}}{2\left(2 b \mu-A^{2}\right)^{2}\left(b+2 \lambda \sigma^{2}\right)^{2}\left[4 b \mu\left(b+\lambda \sigma^{2}\right)-A^{2}\left(b+2 \lambda \sigma^{2}\right)\right]^{2}} .
\end{aligned}
$$

In order to ensure that the requested interval is meaningful, it should satisfy $K_{1}<K_{2}$. The cost-sharing and compensation strategy can make the supply chain achieve perfect coordination, and the compensation amount $K$ depends on the bargaining power of both parties in the game.

\section{Data Availability}

The numerical experiment in this paper is mainly based on the inferred conclusion in this paper; the data used to support the findings of this paper are included within the paper, and they are true and reliable. If readers need related data, they can contact the authors.

\section{Conflicts of Interest}

The authors declare that there are no conflicts of interest regarding the publication of this paper.

\section{Acknowledgments}

This research was funded by the National Natural Science Foundation of China (Grant no. 71771055); Fuyang City Science and Technology Special Fund City and School Cooperation Project (Grant no. SXHZ202009); and Project of Cultivating Outstanding and Top Talents in Universities of Anhui Province in 2021.

\section{References}

[1] L. Yang, R. Tang, and K. Chen, "Call, put and bidirectional option contracts in agricultural supply chains with sales effort," Applied Mathematical Modelling, vol. 47, pp. 1-16, 2017.

[2] H. Sepideh, "This is no time to allow for food loss, waste," 2021.

[3] M. Ferguson, V. Jayaraman, and G. C. Souza, "Note: an application of the EOQ model with nonlinear holding cost to inventory management of perishables," European Journal of Operational Research, vol. 180, no. 1, pp. 485-490, 2006.

[4] M. Bakker, J. Riezebos, and R. H. Teunter, "Review of inventory systems with deterioration since 2001," European Journal of Operational Research, vol. 221, no. 2, pp. 274-284, 2012.
[5] L. X. Shen, F. C. Li, and C. C. Li, "Inventory optimization of fresh agricultural products supply chain based on agricultural superdocking," Journal of Advanced Transportation, vol. 2020, Article ID 2724164, 13 pages, 2020.

[6] X. L. Su and Z. H. Ma, "Pricing and inventory decisionmaking of fresh agricultural products that are out of stock under the condition of advance payment," Chinese Management Science, vol. 24, no. S1, pp. 617-625, 2016.

[7] L. Lu, Q. H. Zhao, and M. Goh, "Perishable material sourcing and final product pricing decisions for two-echelon supply chain under price-sensitive demand," Computers \& Industrial Engineering, vol. 15614 pages, 2021.

[8] H. Wen and J. P. Tao, "Differential pricing and coordination strategies in the supply chain of heterogeneous fresh agricultural products," Mathematics in Practice and Understanding, vol. 48, no. 16, pp. 8-17, 2018.

[9] L. Li and T. J. Fan, "A comparative study on the pricing strategies of fresh agricultural products supply chain under the domination of retailers," Chinese Management Science, vol. 23, no. 12, pp. 113-123, 2015.

[10] X. X. Hu and G. G. Zhou, "Ordering strategy of organic agricultural products with one-way substitution under fuzzy demand," Industrial Engineering and Management, vol. 24, no. 6, pp. 54-63, 2019.

[11] Q. Deng, "Fresh agricultural product ordering strategy based on deterioration and loss," Statistics and Decision, vol. 6, pp. 41-44, 2013.

[12] L. Liu, L. Zhao, and X. Ren, "Optimal preservation technology investment and pricing policy for fresh food," Computers \& Industrial Engineering, vol. 135, no. 9, pp. 746-756, 2019.

[13] S. Makoena and A. Olufemi, "A three-echelon supply chain for economic growing quantity model with price-and freshness-dependent demand: pricing, ordering and shipment decisions," Operations Research Perspectives, vol. 715 pages, 2020.

[14] Y. Sheff, "Supply chain management under the threat of international terrorism," The International Journal of Logistics Management, vol. 12, no. 2, pp. 1-11, 2001.

[15] I. Bjørn and B. D. Bendiksen, "Technological changes: the impact on the raw material flow and production," European Journal of Operational Research, vol. 144, no. 2, pp. 237-246, 2003.

[16] P. Arthon and L. Kannapon, "Managing changes and risk in seafood supply chain: a case study from Thailand," Aquaculture, vol. 52514 pages, 2020. 
[17] J. M. Jia, Z. J. Cui, and Y. J. Lu, "Fresh agricultural product supply chain risk identification and control based on social network analysis," Modern Agriculture, vol. 12, pp. 41-43, 2018.

[18] J. Y. Feng, B. Y. Yuan, X. Li, D. Tian, and W. Mu, "Evaluation on risks of sustainable supply chain based on optimized BP neural networks in fresh grape industry," Computers and Electronics in Agriculture, vol. 18311 pages, 2021.

[19] S. A. Raza and S. M. Govindaluri, "Pricing strategies in a dualchannel green supply chain with cannibalization and risk aversion," Operations Research Perspectives, vol. 616 pages, 2019.

[20] Y. J. Liu and X. Y. Yue, "Decision-making of dual-channel supply chain of agricultural products under different supply and demand," System Science and Mathematics, vol. 39, no. 11, pp. 1808-1822, 2019.

[21] F. Ye, Q. Lin, and Y. Li, "Company+farmer type order agricultural supply chain coordination contract mechanism based on CVaR," System Engineering Theory and Practice, vol. 31, no. 3, pp. 450-460, 2011.

[22] G. P. Cachon, "Supply chain coordination with contracts," Handbooks in Operations Research and Management Science, vol. 11, pp. 229-339, 2003.

[23] B. Yan, X. X. Chen, C. Y. Cai et al., "Supply chain coordination of fresh agricultural products based on consumer behavior," Computers and Operations Research, vol. 123, no. 11, pp. 1-9, 2020.

[24] Y.-B. Xiao, J. Chen, and X.-L. Xu, "Fresh product supply chain coordination under CIF business model with long distance transportation," Systems Engineering - Theory \& Practice, vol. 28, no. 2, pp. 19-34, 2008.

[25] X. Ma, S. Wang, S. M. N. Islam, and X. Liu, "Coordinating a three-echelon fresh agricultural products supply chain considering freshness-keeping effort with asymmetric information," Applied Mathematical Modelling, vol. 67, pp. 337-356, 2019.

[26] I. Moon, Y. J. Jeong, and S. Saha, "Investment and coordination decisions in a supply chain of fresh agricultural products," Operational Research, vol. 20, no. 6, pp. 1-25, 2018.

[27] D. P. Wang, M. Y. Zhu, and T. T. Wang, "Study on the cost sharing contract of freshness supply chain preservation efforts," Industrial Engineering and Management, vol. 25, no. 2, pp. 36-43, 2020.

[28] H. Mohammadi, M. Ghazanfari, M. S. Pishvaee, and E. Teimoury, "Fresh-product supply chain coordination and waste reduction using a revenue-and-preservation-technology-investment-sharing contract: a real-life case study," Journal of Cleaner Production, vol. 213, no. 10, pp. 262-282, 2019.

[29] F. Ye, Q. Lin, and Y. Li, “Coordination for contract farming supply chain with stochastic yield and demand under CVaR criterion," Operational Research, vol. 20, no. 1, pp. 369-397, 2020 . 